\title{
Altered Sensory Experience Exacerbates Stable Dendritic Spine and Synapse Loss in a Mouse Model of Huntington's Disease
}

\author{
Reena Prity Murmu, ${ }^{1}$ Wen Li, ${ }^{1}$ Zsuzsanna Szepesi, ${ }^{1}$ and Jia-Yi Li ${ }^{1,2}$ \\ ${ }^{1}$ Neural Plasticity and Repair Unit, Wallenberg Neuroscience Center, Department of Experimental Medical Sciences, Lund University, BMC A10, 22184 \\ Lund, Sweden, and 'Neuroscience Institute, College of Life and Health Sciences, Northeastern University, Shenyang 110015, People's Republic of China
}

\begin{abstract}
A key question in Huntington's disease (HD) is what underlies the early cognitive deficits that precede the motor symptoms and the characteristic neuronal death observed in HD. The mechanisms underlying cognitive symptoms in HD remain unknown. Postmortem HD brain and animal model studies demonstrate pathologies in dendritic spines and abnormal synaptic plasticity before motor symptoms and neurodegeneration. Experience-dependent synaptic plasticity caused by mechanisms such as LTP or novel sensory experience potentiates synaptic strength, enhances new dendritic spine formation and stabilization, and may contribute to normal cognitive processes, such as learning and memory. We have previously reported that under baseline conditions (without any sensory manipulation) neuronal circuitry in $\mathrm{HD}$ (R6/2 mouse model) was highly unstable, which led to a progressive loss of persistent spines in these mice, and that mutant huntingtin was directly involved in the process. Here, we investigated whether pathological processes of HD interfere with the normal experience-dependent plasticity of dendritic spines in the R6/2 model. Six weeks of two-photon in vivo imaging before and after whisker trimming revealed that sensory deprivation exacerbates loss of persistent-type, stable spines in R6/2 mice compared with wild-type littermates. In addition, sensory deprivation leads to impaired transformation of newly generated spines into persistent spines in R6/2 mice. As a consequence, reduced synaptic density and decreased PSD-95 protein levels are evident in their barrel cortical neurons. These data suggest that mutant huntingtin is implicated in maladaptive synaptic plasticity, which could be one of the plausible mechanisms underlying early cognitive deficits in HD.
\end{abstract}

Key words: cognitive dysfunction; dendritic spines; Huntington's disease; sensory deprivation; synaptic plasticity

\section{Introduction}

Huntington's disease (HD) is an autosomal-dominant disorder caused by expansion of CAG triplets in the gene huntingtin (Huntington's Disease Collaborative Research Group, 1993). Motor symptoms in HD are caused by degeneration of neurons in the striatum and cerebral cortex. However, nonmotor symptoms (e.g., cognitive deficits), which precede overt motor symptoms and neurodegeneration, are caused by early cellular dysfunction (Milnerwood and Raymond, 2007; Schippling et al., 2009; Orth et al., 2010). The mechanisms underlying cognitive deficits in HD remain unclear. A key neuropathological feature, which is evi-

\footnotetext{
Received Jan. 19, 2014; revised Nov. 4, 2014; accepted Nov. 6, 2014.

Author contributions: R.P.M. and J.-Y.L. designed research; R.P.M., W.L., and Z.S. performed research; R.P.M. contributed unpublished reagents/analytic tools; R.P.M. analyzed data; R.P.M. and J.-Y.L. wrote the paper.

This research was supported by the Swedish Research Council, BAGADILICO-Excellence in Parkinson's and Huntington's Research, Multipark Translational Research Program, the ERA-Net Neuron Program (nEUROsyn), Petrus och Augusta Hedlunds Stiftelse, Tore Nilsson Stiftelse, and Thorsten och Elsa Segerfalks Stiftelse. We thank Andrew C. McCourt for the linguistic revision of the manuscript.

The authors declare no competing financial interests.

Correspondence should be addressed to Dr. Jia-Yi Li at either Neural Plasticity and Repair Unit, Wallenberg Neuroscience Center, Department of Experimental Medical Science, Lund University, Sölvegatan 17, BMC A10, 221 84 Lund, Sweden, E-mail: jia-yi.li@med.lu.se; or Neuroscience Institute, College of Life and Health Sciences, Northeastern University, Shenyang 110015, People's Republic of China. E-mail: jiayili@mail.neu.edu.cn.

DOI:10.1523/JNEUROSCI.0244-14.2015

Copyright $\odot 2015$ the authors $\quad 0270-6474 / 15 / 350287-12 \$ 15.00 / 0$
}

dent early in HD, is alterations in "dendritic spines" (Graveland et al., 1985; Ferrante et al., 1991; Spires et al., 2004b; Heck et al., 2012). Although HD is a genetically inherited disorder, it is affected by environmental factors. Remotivation therapy benefits HD patients, whereas enhancing sensory, cognitive, and motor stimulation by environmental enrichment in HD transgenic mice delays the onset of motor and cognitive symptoms, and induces beneficial changes in the brain (Georgiou et al., 1999; van Dellen et al., 2000; Sullivan et al., 2001; Hockly et al., 2002; Spires et al., 2004a).

Functional neuronal circuits in adult neocortex adapt to activity-dependent modulations (e.g., LTP and novel sensory experiences) that underlie synaptic plasticity, learning, memory, and adaptation to sensory experience (Holtmaat et al., 2006). However, in a neurodegenerative disease (e.g., HD), synaptic circuits may not be properly tuned by novel sensory experience (Nithianantharajah and Hannan, 2013). In the rodent barrel cortex, inputs corresponding to individual whiskers on the mystical pad are spatially segregated in barrels in layer 4 (Woolsey and Van der Loos, 1970). Deprivation of sensory input by whisker trimming causes experience-dependent alterations in the receptive field, including enhanced formation and stabilization of new spines in the barrel cortical neurons (Glazewski and Fox, 1996; Fox and Wong, 2005; Holtmaat et al., 2006). Interestingly, abnor- 
mal synaptic plasticity and deficits in learning tasks that require intact barrel cortex have been reported in HD models (Murphy et al., 2000; Mazarakis et al., 2005). However, the underlying mechanisms remain largely unknown. Additionally, it remains unknown how functional neuronal circuitry in HD is regulated by sensory deprivation.

We have previously demonstrated that in $\mathrm{R} 6 / 2$ mice under baseline conditions, mutant huntingtin causes a progressive loss of persistent-type spines, which represent intact neuronal circuitry and are the site of long-term memory in the brain (Murmu et al., 2013). Here, we examined experience-dependent dendritic spine remodeling in R6/2 mice (crossed with Thyl-GFPM mice), using in vivo two-photon imaging, which allows us to longitudinally track individual spines simultaneously during experiencedependent plasticity and as the disease progresses. Our results show that the loss of persistent-type, mature spines is exacerbated after whisker trimming in R6/2*Thy1-GFP mice compared with Thyl-GFP littermates, and that these mice display failure in transformation of newly generated spines into persistent spines. As a consequence, synaptic density and postsynaptic density-95 (PSD-95) protein levels are significantly reduced in the R6/2 mice. This deficit in experience-dependent synaptic plasticity, observed in the HD model, R6/2, could potentially be a plausible mechanism underlying early cognitive deficits observed in HD.

\section{Materials and Methods}

Transgenic mice. All animal procedures were performed in accordance with the protocols approved by the animal care welfare committee of Lund University (Lund, Sweden). All mice were kept under a normal $12 \mathrm{~h}$ light/dark cycle, and had access to food and water ad libitum. A colony of $\mathrm{R} 6 / 2$ mice was maintained by crossing R6/2 ${ }^{+/-}$males with F1 of C57BL/ $6 \times$ CBA hybrid females. The colony of Thyl-GFP-M was maintained on F1 background by crossing Thy1-GFP-M males or females with C57BL/6 females or males. Heterozygous female Thyl-GFP-M mice were crossed with heterozygous R6/2 male mice (F1 hybrids of R6/2 ${ }^{+/-}$males $\times$ hybrid of C57BL/ $6 \times$ CBA females) to produce double-transgenic reporter mice (i.e., R6/2 ${ }^{+/-}$-Thyl-GFP-M $\mathrm{M}^{+/-}$) for time-lapse imaging. Throughout the text, we will refer to these double-transgenic reporter mice as R6/2*Thy1-GFP mice (HD mice), and single-transgenic reporter mice (i.e., R6/2 $2^{-1-}$-Thy1-GFP-M ${ }^{+/-}$) as Thy1-GFP (wild-type) mice. Thyl-GFP-M is a transgenic reporter line in a C57BL/6 background that expresses cytoplasmic GFP in a sparse subset of layer II/III and V cortical neurons (Feng et al., 2000). This model has been widely used by twophoton in vivo imaging studies to monitor the dynamic behavior of cortical neurons, particularly of dendritic spines and axons (De Paola et al., 2006; Holtmaat et al., 2006; Wilbrecht et al., 2010; Murmu et al., 2013). In the HD model R6/2, exon 1 of the human huntingtin gene containing 141-157 CAG repeats is overexpressed under the control of human huntingtin promoter (Mangiarini et al., 1996). The CAG repeat lengths were verified for each mouse by sequencing. In our R6/2 mice, the repeat length ranged between 255 and 280 CAGs.

Sensory deprivation. Several methods of whisker trimming, such as complete whisker deprivation and a unilateral or bilateral chessboard pattern of whisker deprivation, have been established to study experience-dependent plasticity of dendritic spines (Wallace and Fox, 1999). The sensory deprivation paradigm that we used in our study consisted of trimming all the whiskers of an anesthetized mouse every alternative day from the contralateral left mystical pad, starting at postnatal day 65 (P65) to P81. In this model, the mice underwent complete whisker deprivation on the left whisker pad (ipsilateral side), and two-photon in vivo imaging was performed on the right somatosensory cortex (contralateral side).

Surgery and time-lapse in vivo imaging. Cranial windows were implanted on 1-month-old isoflurane-anesthetized $[1.5 \%(\mathrm{v} / \mathrm{v})$ maintenance] single-transgenic (R6/2 $2^{-1-}$ Thyl-GFP-M ${ }^{+/-}$or Thyl-GFP) and double-transgenic $\left(\mathrm{R} 6 / 2^{+/-}-\right.$Thyl-GFP-M ${ }^{+/-}$or R6/2*Thyl-GFP) re- porter mice, as previously described (Murmu et al., 2013). Briefly, the skull overlying the right somatosensory cortex (from bregma: AP -1.5 $\mathrm{mm}$; lateral $-3.5 \mathrm{~mm}$ ) was removed and replaced with a small coverslip ( $5 \mathrm{~mm}$ in diameter), keeping the dura intact (Fig. 1A). Imaging was carried out every eighth day starting from P41 to P81 using a two-photon upright camera (7 megapixel, LSM Axiocam MRM, Zeiss) microscope equipped with a tunable Ti:sapphire ultrafast oscillating laser (Mai Tai, Spectra Physics) and a $12 \mathrm{~W}$ solid-state pump laser. For imaging, the laser was tuned to $900 \mathrm{~nm}$ to excite EGFP. After baseline imaging for 3 weeks (P41-P57), whiskers were trimmed on the contralateral left mystical pad, and spines were imaged for 3 additional weeks (P65-P81; Fig. 1B, experimental timeline). We had four different experimental groups in this study, as follows: (1) nontrimmed Thy1-GFP mice (wild types) in which whiskers were kept intact for the entire imaging period of 6 weeks; (2) trimmed Thyl-GFP mice in which whiskers were kept intact for 3 weeks and then trimmed every other day for the next 3 weeks to induce plasticity; (3) nontrimmed R6/2*Thy1-GFP mice-same as nontrimmed Thy1GFP mice; and (4) trimmed R6/2*Thy1-GFP mice-same as trimmed Thyl-GFP mice. In each animal, apical dendritic tufts of pyramidal neurons with soma position in layer II/III and V were imaged over a period of 6 weeks. Apical dendritic tufts of pyramidal neurons, which were imaged, are located in L1 and L2. The unique vascular pattern was captured with a Canon PowerShot A650 camera and was used to relocate the same dendritic segments over subsequent imaging sessions. Imaging was carried out every eighth day starting from P41 to P81. Images were acquired using a $20 \times$ objective (numerical aperture 1.0). Lower-resolution image stacks $(512 \times 512$ pixels, $\times 1.0$ zoom, and $1.0 \mu \mathrm{m}$ step size $)$ were acquired to visualize the dendritic branching pattern and the position of the soma. For higher-magnification spine imaging, 5-15 random apical dendritic tufts (per mouse) each $42.51 \times 42.51 \mu \mathrm{m}$, up to $300 \mu \mathrm{m}$ below the pial surfaces, were imaged. For spines, image stacks with a digital zoom of $\times 10,512 \times 512$ pixels $(0.08 \mu \mathrm{m} /$ pixel $)$ taken at $0.6 \mu \mathrm{m}$ increments were collected. Care was taken to ensure similar fluorescence across imaging sessions. To avoid phototoxicity, the lowest laser power that could discern all spines was used. Scanning and image acquisitions were controlled by Zen 2009 software from Zeiss.

Image processing and data analysis. Image processing and data analysis were performed using the National Institutes of Health (NIH)-based public domain software ImageJ, according to published methods (Holtmaat et al., 2005; Murmu et al., 2013). All images in the study are 3-D projected $Z$-stacks. Before projections, images were low-pass and median filtered. In some figures, distracting fluorescent processes were removed. Dendritic spines were counted manually by scrolling through the $Z$-stacks of subsequent time points of the same position. All clear protrusions, regardless of their shape (stubby, mushroom, thin spines), emanating laterally from the dendrite, not above or below the dendrite, were measured. Analysis was performed blindly, with the analyzer unaware of the experimental conditions. Only frames with good signal-to-noise ratio, where spines on all parts of the dendrite were clearly visible, were used for analysis, dim frames were discarded. Spines were considered the same between two views on the basis of their spatial relationship to adjacent landmarks and their relative position to immediately adjacent spines. Spines were considered different if they were $>0.5 \mu \mathrm{m}$ away from their previous position. Because the two-photon microscope has a relatively poor resolution in the $z$-axis, only protrusions emanating in the $x-y$ directions were included. We focused our analysis on persistent spines, which were defined as spines that survived for $\geq 8 \mathrm{~d}$. The always-present" (AP) spine represents spines that were present throughout the entire imaging period of 6 weeks. "New persistent" (NP) spines were defined as spines that were gained during the imaging session and that remained present until the next imaging session or longer (i.e., $\geq 8 \mathrm{~d}$; for the definition of spine categories, see Figs. 1C, 2C). "Lost persistent" (LP) spines were defined as spines that were present for at least two imaging sessions (i.e., $8 \mathrm{~d}$ ) and then disappeared in subsequent imaging sessions (Fig. 1C). "Total new" (TN) spines were defined as spines that were gained throughout the entire imaging period of 6 weeks. We analyzed a total of two to three neurons/animal. A total of 715 dendritic spines, which were present throughout the entire imaging period of 6 weeks, were followed ( $N=6-8$ animals/group). In this study, we did not find any significant 
A

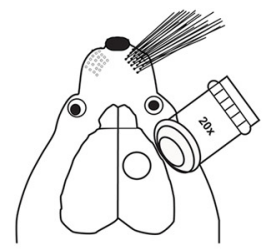

D

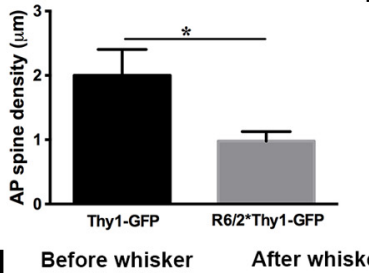
$\begin{array}{cc}\text { H } \begin{array}{c}\text { Before whisker } \\ \text { trimming } \\ \text { (PND 41-57) }\end{array} & \begin{array}{c}\text { After whiske } \\ \text { trimming }\end{array} \\ \text { (PND 65-81) }\end{array}$

B

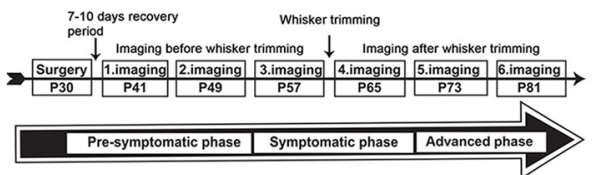

E

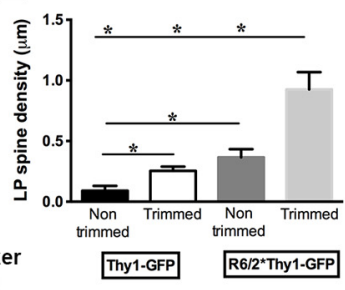

F

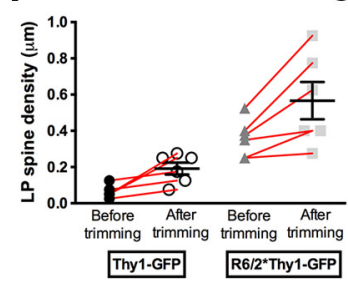

C

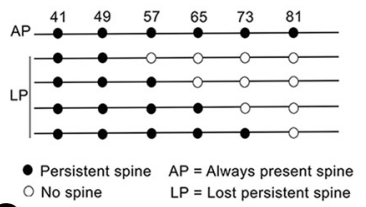

G

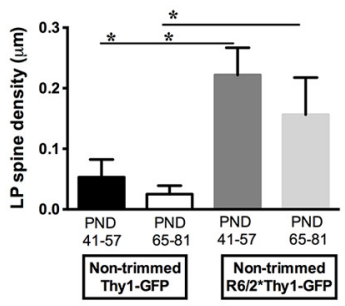

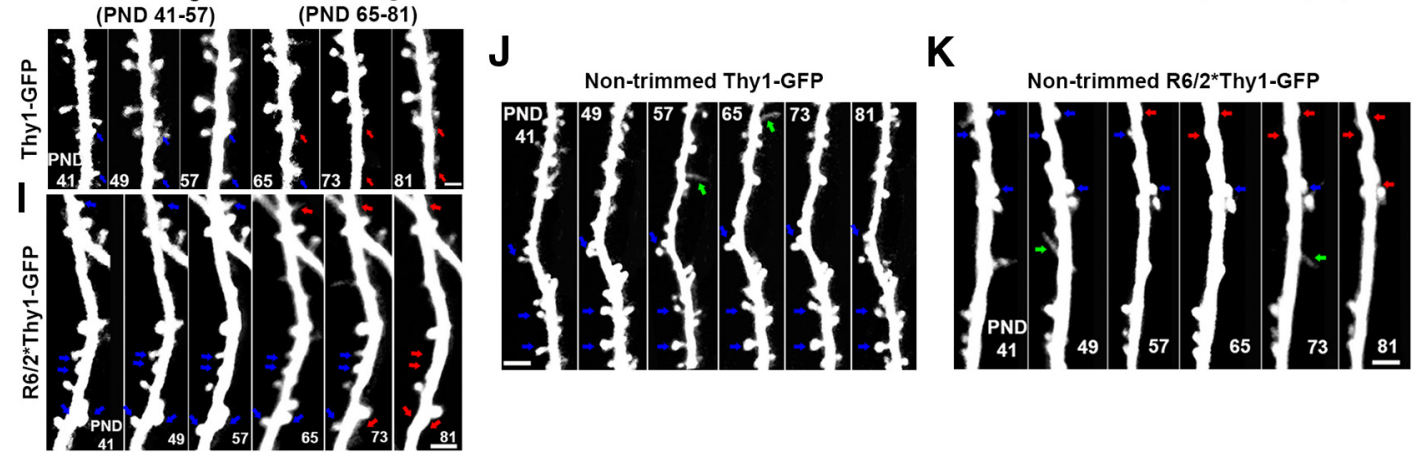

Figure 1. Sensory deprivation exacerbates the loss of persistent-type mature spines in $\mathrm{R} 6 / 2$ mice compared with wild-type mice. $A$, Schematic of a cranial window on the somatosensory cortex where the imaging was performed. $\boldsymbol{B}$, Timeline for imaging. $\boldsymbol{C}$, Definition of spine categories: $41,49,57,65,73$, and 81 represent imaging days. $\boldsymbol{D}$, AP spine density, which is significantly lower in R6/2*Thy1-GFP mice compared with Thy1-GFP mice (wild types) during the 6 week imaging period. E, LP spine density in nontrimmed and trimmed Thy1-GFP and R6/2*Thy1-GFP mice. Trimmed mice lose more persistent spines compared with nontrimmed mice of both genotypes. F, Comparison of LP spine density before and after whisker trimming in trimmed Thy 1-GFP and R6/2*Thy1-GFP mice. Before whisker trimming, Thy1-GFP mice do not lose any persistent spines; however, after whisker trimming, persistent spines are lost in the barrel cortical neurons of these mice. In contrast, R6/2*Thy1-GFP mice have already lost significantly more persistent spines, before whiskers are trimmed. After whisker trimming, persistent spine loss is exacerbated in R6/2*Thy1-GFP mice. G, LP spine density in an independent group of age-matched nontrimmed Thy1-GFP and R6/2*Thy1-GFP mice during P41-P57 and P65-P81. No difference in dendritic spine density is observed between P41 and P57, and between P65 and P81. $\boldsymbol{H}$, Time-lapse image of a dendritic branch from Thy1-GFP mouse showing the loss of two persistent spines after whisker trimming (red arrows). $\boldsymbol{I}$, Time-lapse image of a dendritic branch from R6/2*Thy1-GFP mouse indicating the loss of five persistent spines after whisker trimming (see red arrows on P81). $J, K$, Time-lapse image of a dendritic branch from an independent group of nontrimmed Thy1-GFP mice $(\boldsymbol{J})$ and nontrimmed R6/2*Thy1-GFP mice $(\boldsymbol{K})$ that loses significantly more persistent spines (red arrows) compared with Thy1-GFP mice, regardless of age. Representative dendrites (time-lapse images) are from layer II/III of the cortex. Blue arrows indicate persistent spines, while green arrows indicate new spines. Asterisks indicate significant differences between groups. Data are presented as the mean \pm SEM. Means were considered to be statistically significant if $p<0.05 . \mathrm{N}=6$ mice/group. Scale bars, $2 \mu \mathrm{m}$.

difference in spine plasticity between layer II/III and V. Hence, the data from both of these layers were pooled for analyses.

Electron microscope. On the final day of imaging, mice were transcardially perfused with $4 \%$ paraformaldehyde and $2 \%$ EM-grade glutaraldehyde in $0.1 \mathrm{~m}$ phosphate buffer (PB), pH 7.4. Right somatosensory cortex, where in vivo imaging was performed, was marked with a toluidine blue solution. One-millimeter-thick tissue blocks were cut across the contralateral and ipsilateral cortex (right and left hemisphere). Slices were then washed in Sorensen phosphate buffer $(0.1 \mathrm{M}), \mathrm{pH} 7.4$, stained in $1 \%$ osmium tetroxide in $\mathrm{PB}$ for $2 \mathrm{~h}$. Stained sections were dehydrated in ascending grades of acetone ranging from $30 \%$ to $100 \%$ and were embedded in PolyBed 812 Epoxy Resin. For immunoelectron microscopy, the sections were treated first with sodium periodate $\left(\mathrm{NaIO}_{4}\right)$ to inactivate osmium and then treated with $0.05 \mathrm{~m}$ glycine in PBS to inactivate the aldehyde. Thereafter, the sections were blocked in $0.5 \%$ bovine albumin serum (BSA) and incubated overnight at $4^{\circ} \mathrm{C}$ with the following primary antibodies: anti-rabbit PSD-95 (1:500; Abcam); anti-rabbit synaptophysin (1:200; Abcam); and anti-mouse vesicular glutamate transporter (VGLUT; 1:100; Abcam), respectively. For the negative control group, the sections were incubated in $0.5 \%$ BSA containing no primary antibody. After overnight incubation, the sections were incubated in 10 $\mathrm{nm}$ gold-conjugated goat anti-rabbit or goat anti-mouse secondary antibody (1:20) for $1 \mathrm{~h}$ at room temperature. The region of interest (somatosensory cortex) was cut from the hardened section and serially sectioned at $60 \mathrm{~nm}$ thickness using EM UC7 ultratome (Leica). The sections were collected on single-slot grids, stained with $4 \%$ uranyl acetate for $20 \mathrm{~min}$ at $39^{\circ} \mathrm{C}$ and $0.5 \%$ lead citrate for $2 \mathrm{~min}$ in room temperature, and then imaged in a transmission electron microscope (Tecnai BioTWIN, FEI) operating at $100 \mathrm{kV}$ tension with a Veleta digital camera. A total of nine random grids from each area (spared cortex, deprived cortex) were sampled for R6/2*Thy1-GFP mice and Thy1-GFP mice (wild type) to quantify asymmetric (presumably excitatory) synapses. Per grid, 25 random images were acquired at $21,500 \times$ magnification for the quantification of synapses. A few high-magnification images were acquired at $43,000 \times$ for the characterization of asymmetrical synapses. Image alignment was carried out in Paintshop Pro (PSP) software. Morphological analysis and quantification of synaptic density (asymmetrical synapses) were carried out in the Cell Counter plugin embedded in NIHbased public domain software ImageJ.

Western blotting. Mouse brain tissues were collected and stored at $-80^{\circ} \mathrm{C}$ until use. Tissue samples from 6-, 8-, and 12-week-old R6/2 mice and wild-type littermates were resuspended in $200 \mu \mathrm{l}$ of lysis buffer per $10 \mathrm{mg}$ sample, and thereafter, using a razor, tissue samples were cut into small blocks containing either the contralateral somatosensory cortex (right hemisphere) or the ipsilateral somatosensory cortex (left hemisphere). Subsequently, the samples were sonicated (Qsonica) for $1 \mathrm{~min}$ $\left(2 \times \sim 30\right.$ strokes, $10 \mathrm{~s}$ with $5 \mathrm{~s}$ intervals at $\left.4^{\circ} \mathrm{C}\right)$, spun at $8000 \times g$ at $4^{\circ} \mathrm{C}$ for $30 \mathrm{~min}$. Protein concentration of supernatant was determined by a BCA Protein Assay Kit (Pierce) and then a 1:4 solution of $5 \times$ loading buffer plus $10 \%$ DTT was added to the samples. After incubation for 5 
A

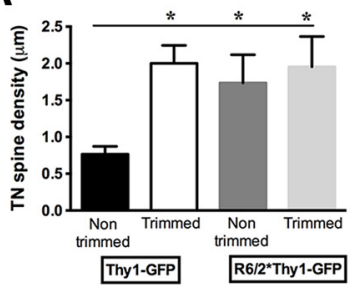

D

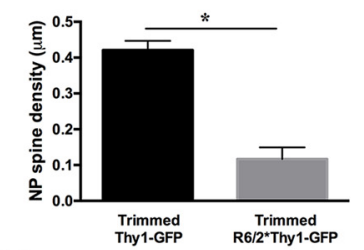

H

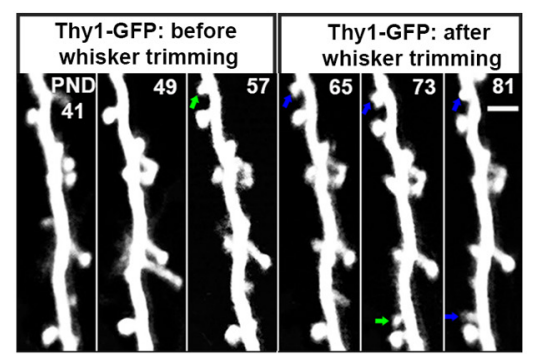

B

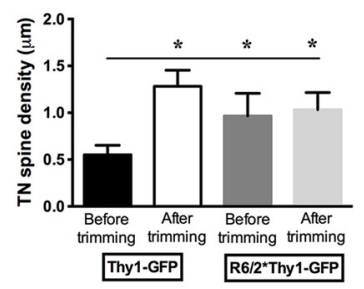

C

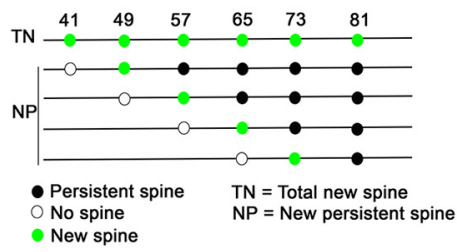

G
E

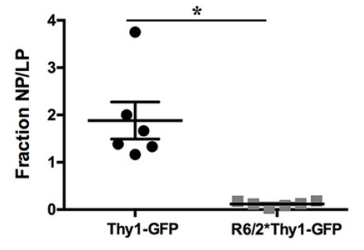

F
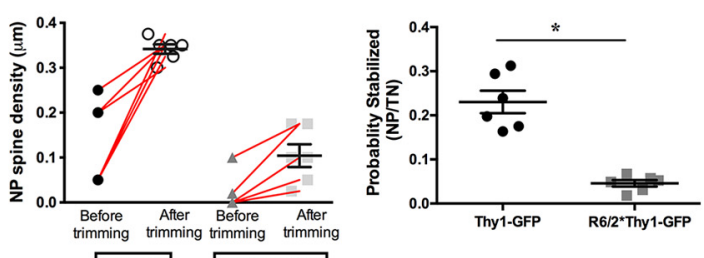

I

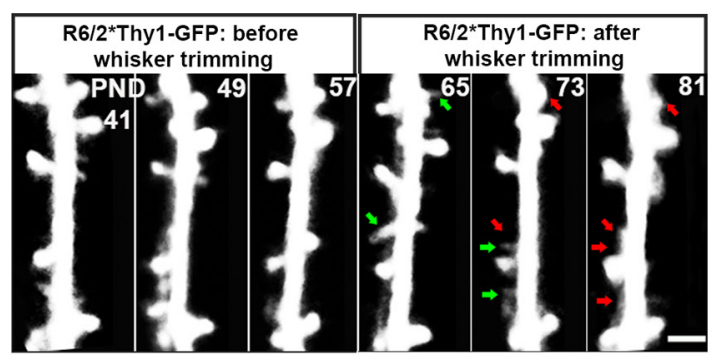

Figure 2. Failure in transformation of newly generated spines into stable, persistent spines after sensory deprivation in R6/2 mice. $A$, TN spine density in nontrimmed and trimmed mice of both genotypes. Significantly more new spines are generated in trimmed mice compared with nontrimmed mice. Moreover, in R6/2*Thy1-GFP mice, more new spines are generated regardless of whisker trimming. B, Comparison of TN spine density before and after whisker trimming in trimmed R6/2*Thy1-GFP and Thy1-GFP mice. C, Definition of spine categories 41,49,57,65, 73, and 81 represent imaging days. D, NP spine density in trimmed mice of both genotypes. Trimmed R6/2*Thy1-GFP mice clearly show significantly lower NP spine density compared with trimmed Thy1-GFP mice. $\boldsymbol{E}$, Fraction of NP/LP spines, which is significantly lower in R6/2*Thy1-GFP mice compared with Thy1-GFP mice. $F$, Comparison of NP spine density before and after whisker trimming in trimmed mice of both genotypes. In Thy1-GFP mice, whisker trimming enhanced the transformation of newly generated spines into persistent spines. However, in R6/2*Thy1-GFP mice, transformation of newly generated spines into persistent spines was significantly lower compared with Thy1-GFP mice. Circles and squares represent individual mice. G, Comparison of probability of new spines to stabilize or to become persistent in R6/2*Thy1-GFP mice compared with Thy1-GFP mice. The probability of new spines becoming persistent is significantly lower in R6/2*Thy1-GFP mice compared with Thy1-GFP mice. $\boldsymbol{H}$, Time-lapse image of a dendritic branch from a trimmed Thy1-GFP mouse (before and after whisker trimming), showing the generation of two persistent spines after whisker trimming (blue arrows, P81). I, Time-lapse image of a dendritic branch from an R6/2*Thy1-GFP mouse, showing failure in the transformation of newly generated spines into persistent spines. New spines (indicated by green arrow) in the R6/2*Thy1-GFP mouse are subsequently lost (indicated by red arrows) after their generation. Representative dendrites (time-lapse images) are from layer $\mathrm{V}$ of the cortex. Asterisks indicate significant differences between groups. Data are presented as the mean \pm SEM. Means were considered to be statistically significant at $p<0.05$. $N=6-8$ mice/group. Scale bars, $2 \mu \mathrm{m}$.

min at $95^{\circ} \mathrm{C}$, samples were loaded for SDS-PAGE on $12 \%$ polyacrylamide gels and then subjected to Western blot transfer. The membrane was blocked for $1 \mathrm{~h}$ in blocking solution containing PBS with $0.05 \%$ Tween plus $5 \%$ milk. Primary antibodies used for Western blotting were rabbit anti-PSD-95 antibody (1:1000; Abcam), mouse anti $\beta$-actin (1:1000; Abcam), and mouse anti- $\alpha$-tubulin (1:1000). After washing $3 \times$ for $10 \mathrm{~min}$ in PBS, the membrane was incubated in secondary antibodies, which include goat anti-rabbit and goat anti-mouse horseradish peroxidaseconjugated antibodies from Dako used at 1:10,000 dilutions. Membranes were developed (for PSD-95, $\beta$-actin, and $\alpha$-tubulin separately) using a luminol kit from Santa Cruz Biotechnology in a ChemiDoc machine from Bio-Rad. Quantitative Western blot data were obtained and analyzed in Image Lab.

Subcellular fractionation. Fresh brain tissues containing the cortex was grossly dissected out and washed a few times in Krebs buffer to remove traces of blood. It was then homogenized with a few up/down strokes in a glass homogenizer using $2 \times$ Krebs buffer $(125 \mathrm{~mm} \mathrm{NaCl}, 1.2 \mathrm{~mm}$ $\mathrm{MgSO}_{4}, 2.5 \mathrm{~mm} \mathrm{CaCl}_{2}, 1.5 \mathrm{~mm} \mathrm{KH}_{2} \mathrm{PO}_{4}, 25 \mathrm{~mm} \mathrm{NaHCO}_{3}, 213 \mathrm{~mm}$ glucose, $\mathrm{pH} 7.4$, containing protease inhibitor) until a smooth homogenate was obtained. Homogenate was then filtered through prewetted 100, 60, 30, and $10 \mu \mathrm{m}$ filters (Nylon Net Filters, Millipore). The supernatant was collected and centrifuged at $1000 \times g$ for $15 \mathrm{~min}$ at $4^{\circ} \mathrm{C}$ to obtain pellet containing the synaptosomes. The synaptosomes were resuspended in PBS, and loading buffer was added to the pellet for Western blotting, which was performed using the same protocol described above. Primary antibodies used for Western blotting were rabbit anti-PSD-95 antibody $(1: 1000 ;$ Abcam), mouse anti- $\beta$-actin (1:1000; Abcam), and mouse anti$\alpha$-tubulin (1:1000).

Statistics. A two-way ANOVA [genotype $\times$ treatment (whisker trimming)] was performed to analyze significant difference in LP, TN, and NP spine density and synaptic density. Post hoc comparisons were made using Bonferroni's test. All data are presented as the mean \pm SEM $(N=$ 4-8 mice per group). An unpaired $t$ test (two tailed) was used to test significant differences in AP and NP spine density between Thyl-GFP and R6/2*Thy1-GFP mice. Western blot data were analyzed using a twoway ANOVA statistical method using genotype and age as variables. Differences were considered to be statistically significant at $p<0.05$. All statistical analyses were performed with Prism 6.0 (GraphPad Software).

\section{Results}

Sensory deprivation exacerbates loss of persistent-type, mature spines in $\mathrm{R} 6 / 2$ mice

In vivo studies have revealed the existence of at least two types of dendritic spines, persistent and transient, in the neocortex of a naive mouse (Holtmaat et al., 2005). Persistent spines are typically large, mushroom-like, and stable for weeks or months, whereas transient spines are usually thin and live a short time, 
from hours to several days (Holtmaat et al., 2005). In contrast to transient spines, persistent spines always bear synapses (Holtmaat et al., 2005). Previously, using long-term in vivo imaging, we have shown that under baseline conditions (without any sensory- or activity-dependent manipulations) R6/2 mice display significantly lower persistent-type, mature spines compared with wild-type mice throughout the disease (Murmu et al., 2013). Here, we sought to determine how sensory deprivation (induced by whisker trimming) modulates persistenttype, mature spines in R6/2 mice as the disease progresses.

Inhibiting synaptic activity by whisker trimming is reported to destabilize existing persistent spines and stabilize new dendritic spines in the neocortex of a normal mouse (Fox and Wong, 2005; Holtmaat et al., 2006). We imaged 5-15 apical dendrites of layer $\mathrm{II} / \mathrm{III}$ and $\mathrm{V}$ pyramidal neurons in the right somatosensory cortex (nontrimmed side) of R6/2^Thy1-GFP and Thy1-GFP mice (Fig. 1A). Thy1-GFP mice from line M (Thy1-GFPM) express cytoplasmic GFP in a sparse subset of layer II/III and V cortical neurons, allowing for repeated imaging of dendritic spines, dendrites, and axons by two-photon microscopy (Feng et al., 2000; De Paola et al., 2006; Holtmaat et al., 2006; Wilbrecht et al., 2010). We tracked individual dendritic spines for a period of 6 weeks in HD mice (R6/2*Thy1-GFP) and wild-type mice (Thy1GFP). Whiskers were kept intact during a baseline imaging period of 3 weeks followed by 3 weeks during which all whiskers on the left mystical pad (contralateral to imaging) were trimmed every other day to induce plasticity (Fig. 1A,B). We first focused on AP spines (i.e., spines that were observed through the entire imaging period of 6 weeks; Fig. $1 C$, definition of spine categories). A total of 715 AP dendritic spines were followed over a period of 6 weeks. We found that always-present spine density is significantly lower in R6/2*Thy1-GFP mice compared with Thy1-GFP mice (AP spine density: Thyl-GFP mice, $2.0 \pm 0.40$; R6/2 ${ }^{\star}$ Thy1-GFP mice, $0.97 \pm 0.14 ; p=0.038 ; N=6$ mice/group; unpaired $t$ test, two tailed; Fig. $1 D$ ). Next, we focused on dendritic spines that were present for $\geq 8 \mathrm{~d}$ (i.e., persistent spines) since these spines always bear synapses (Knott et al., 2006). We first analyzed the density of LP spines in nontrimmed and trimmed mice of both genotypes. Trimmed mice (both Thyl-GFP and R6/2*Thy1-GFP mice) demonstrate higher LP spine density compared with nontrimmed mice $\left[F_{(1,24)}=21.57 ; p=0.0001\right.$; effect of treatment (whisker trimming); $N=5-6$ mice/group; two-way ANOVA; Fig. $1 E$ ]. However, trimmed R6/2*Thy1-GFP mice show the highest fraction of LP spine density compared with all other groups $\left(F_{(1,24)}=36.93 ; p<0.0001\right.$; effect of genotype; $N=5-6$ mice/group; two-way ANOVA; Fig. $1 E$; LP spine density: nontrimmed Thy1-GFP mice, $0.09 \pm 0.04$; trimmed Thy1GFP mice, $0.25 \pm 0.03$; nontrimmed R6/2*Thy1-GFP mice, $0.36 \pm 0.06$; trimmed R6/2*Thy1-GFP mice, $0.92 \pm 0.14$ ). Further, quantification of the total number of LP spines revealed 213 LP spines in R6/2*Thy1-GFP mice and 78 in Thyl-GFP mice. Since the trimmed mice, regardless of genotype, demonstrate significantly higher LP spine density (and number) compared with nontrimmed mice, we wanted to determine the period during which the loss of persistent spines occurred in the trimmed mice of both genotypes. Analysis of LP spine density before and after whisker trimming revealed that in both genotypes after the whiskers were trimmed, significantly higher LP spine density occurred compared with before the whiskers were trimmed $\left[F_{(1,20)}\right.$ $=8.39 ; p=0.008$; effect of treatment (whisker trimming); $N=6$ mice/group; two-way ANOVA].

Before whisker trimming, Thyl-GFP (wild-type) mice very rarely lose any persistent spines; however, after whisker trim- ming, Thy1-GFP mice demonstrate a loss of persistent spines (as expected), indicating experience-dependent reorganization of neuronal circuitry in the Thyl-GFP (wild-type) mice (Fig. $1 F, H)$. In contrast, R6/2*Thyl-GFP mice, compared with Thy1GFP mice, already demonstrated significantly higher LP spine density, before the whiskers were trimmed $\left(F_{(1,20)}=33.16, p<\right.$ 0.0001; effect of genotype; $N=6$ mice/group; two-way ANOVA; Fig. $1 F)$. Loss of persistent spines was further worsened in the R6/2*Thy1-GFP mice after whisker trimming (LP spine density: before trimming in Thy1-GFP mice, $0.06 \pm 0.01$; after trimming in Thy1-GFP mice, $0.19 \pm 0.03$; before trimming in R6/2*Thy1GFP mice, $0.35 \pm 0.04$; after trimming in R6/2*Thy1-GFP mice, $0.56 \pm 0.10$; Fig. $1 F, I)$. In the R6/2 mice, the period during which the whiskers were trimmed (i.e., P65-P81) falls within the symptomatic phase of the disease.

To rule out the possibility that increased loss of persistent spines in the R6/2 mice after whisker trimming is caused by the age or the disease state of these mice, we imaged another independent group of age-matched nontrimmed Thyl-GFP and R6/ $2^{\star}$ Thy1-GFP mice from P41 to P57 and from P65 to P81. These periods represent phases during which whiskers were either kept intact (P41-P57) or trimmed (P65-P81) in the whiskertrimming experiment. We did not observe any significant differences in LP spine density between P41 and P57, and P65 and P81 in both genotypes, indicating that age does not have any effect on LP spine density. R6/2*Thy1-GFP mice, regardless of their age (or disease state), show increased LP spine density compared with Thy1-GFP mice $\left(F_{(1,28)}=13.15 ; p=0.0011\right.$; effect of genotype: $N=8$ mice/group, two-way ANOVA; Fig. $1 G, J, K$; LP spine density in nontrimmed Thyl-GFP mice: P41-P57, $0.053 \pm 0.02$; P65-P81, $0.025 \pm 0.014$; nontrimmed R6/2*Thy1-GFP mice: $\mathrm{P} 41-\mathrm{P} 57,0.22 \pm 0.04 ; \mathrm{P} 65-\mathrm{P} 81,0.156 \pm 0.06)$. This finding is consistent with our previous report suggesting that $\mathrm{R} 6 / 2$ mice exhibit a lower fraction of persistent spines throughout the disease. In summary, the results suggest that sensory deprivation exacerbates persistent spine loss in the HD mouse model R6/2.

\section{Failure in transformation of newly generated spines into stable, persistent spines after sensory deprivation in $\mathrm{R} 6 / 2$ mice}

In the mouse neocortex, most of the dendritic spines are persistent, whereas a subset of dendritic spines appears and disappears over days (Holtmaat et al., 2005). Under baseline conditions, the conversion rate from transient spines to persistent ones is low (Holtmaat et al., 2005). In contrast, novel sensory experiences such as whisker trimming have been reported to enhance the formation of new spines and stabilization of newly formed spines in the barrel cortex of a normal mouse (Fox and Wong, 2005; Holtmaat et al., 2006). In our previous study, we have shown that dendritic spine turnover is dramatically increased in R6/2 mice (Murmu et al., 2013). Significantly more dendritic spines appeared and subsequently disappeared in barrel cortical neurons of R6/2 mice compared with wild types. Additionally, we showed that those newly generated spines failed to transform into persistent spines in the R6/2*Thy1-GFP mice.

Here, we wanted to determine whether sensory deprivation (whisker trimming) enhanced transformation of newly generated spines into persistent spines in R6/2*Thyl-GFP mice. We first analyzed TN spines in both genotypes under nontrimmed and trimmed conditions (Fig. 2C, definition of spine categories). Quantification of TN spine density revealed significantly higher TN spine density in trimmed Thyl-GFP mice compared with nontrimmed Thy1-GFP mice $\left[F_{(1,18)}=5.15 ; p=0.035 ; N=5-6\right.$ 
mice/group; effect of treatment (whisker trimming), two-way ANOVA; Fig. 2A]. In contrast, compared with Thy1-GFP mice (wild types), R6/2^Thy1-GFP mice display higher TN spine density under both trimmed and nontrimmed conditions (TN spine density: Thyl-GFP nontrimmed mice, $0.76 \pm 0.10$; Thyl-GFP trimmed mice, $2.0 \pm 0.24$; R6/2 ${ }^{\star}$ Thyl-GFP nontrimmed mice, $1.7 \pm 0.38$; R6/2*Thy1-GFP trimmed mice, $1.9 \pm 0.41$; Fig. $2 A$; total number of new spines: Thy1-GFP mice, 453; R6/2^Thy1GFP mice, 509). Since whisker trimming influenced the generation of newly formed spines, we wanted to compare spine gain before and after whisker trimming in trimmed mice of both genotypes. We found that after whisker trimming $\mathrm{TN}$ spine density is significantly increased in Thy1-GFP mice $\left[F_{(1,20)}=4.8 ; p=\right.$ 0.03; effect of treatment (whisker trimming); $N=6$ mice/group; two-way ANOVA; Fig. 2B]. In contrast, R6/2^Thy1-GFP mice show increased TN spine density both before and after whisker trimming, confirming increased spine gain in the R6/2 Thy1GFP mice $\left(F_{(1,20)}=5.0 ; p=0.04\right.$; effect of genotype; $N=6$ mice/group; two-way ANOVA; Fig. 2B; TN spine density before whisker trimming: Thyl-GFP mice, $0.55 \pm 0.10$; R6/2* Thy1GFP mice, $0.96 \pm 0.24$; TN spine density after whisker trimming: Thyl-GFP mice, $1.28 \pm 0.17$; R6/2 ${ }^{\star}$ Thy1-GFP mice, $1.03 \pm$ 0.18 ). Stabilization of new spines in the barrel cortex is normally enhanced after whisker trimming in mice (Holtmaat et al., 2006). Hence, we determined whether newly formed spines in both genotypes transformed into persistent spines.

Quantification of the total number of new persistent spines revealed $128 \mathrm{NP}$ spines in Thyl-GFP mice and $55 \mathrm{NP}$ spines in R6/2*Thy1-GFP mice. We then calculated NP spine density in Thy1-GFP mice (wild type) and R6/2*Thy1-GFP mice. We found that R6/2^Thyl-GFP mice demonstrate significantly lower NP spine density compared with Thyl-GFP mice (NP spine density: Thyl-GFP mice, $0.42 \pm 0.02 ; \mathrm{R} 6 / 2^{\star}$ Thy1-GFP mice, $0.11 \pm 0.03$; $P=<0.0001$; unpaired $t$ test (two tailed); Fig. $2 D$ ). In addition, the fraction of NP/LP is significantly lower in R6/2*Thyl-GFP mice compared with Thyl-GFP mice, in which more new spines become persistent in relation to the number of persistent spines that are lost (Fig. 2E). Next, we quantified NP spine density before and after whisker trimming in trimmed mice of both genotypes. Analysis of NP spine density before and after whisker trimming revealed that in Thyl-GFP mice NP spine density is significantly increased after whisker trimming, as expected $\left[F_{(1,20)}=34.71 ; P=<0.0001\right.$; effect of treatment (whisker trimming); $N=6$ mice/group; two-way ANOVA; Fig. $2 F, H]$. In contrast, in the R6/2`Thyl-GFP mice, whisker trimming did not influence new persistent spines, as NP spine density continued to remain significantly lower after whisker trimming $\left(F_{(1,20)}=\right.$ 49.94; $p<0.0001$; effect of genotype; $N=6$ mice/group; two-way ANOVA; Fig. 2F, I; NP spine density before whisker trimming: Thyl-GFP mice, $0.13 \pm 0.03$; R6/2 ${ }^{\star}$ Thy 1-GFP mice, $0.02 \pm 0.02$; NP spine density after whisker trimming: Thyl-GFP mice, $0.34 \pm$ $0.01 ; \mathrm{R} 6 / 2^{\star}$ Thyl-GFP mice, $0.10 \pm 0.03$ ). Since new spines fail to convert into persistent spines in R6/2^Thyl-GFP mice, we calculated the probability that new spines would become persistent in R6/2*Thy1-GFP mice compared with Thy1-GFP mice. We found that the probability of new spines becoming persistent was significantly reduced in R6/2*Thyl-GFP mice compared with Thyl-GFP mice (Fig. 2G). These data imply that the HD mouse model R6/2 displays deficits in experiencedependent stabilization of newly formed dendritic spines on barrel cortical neurons.

\section{Sensory deprivation exacerbates loss of synapses in the barrel cortical neurons of $\mathrm{R} 6 / 2$ mice}

To evaluate whether loss of persistent-type spines in the barrel cortical neurons of R6/2 mice induced by whisker trimming reflects a true loss of synapses, we performed quantitative electron microscopy to quantify synaptic density on barrel cortical neurons of both genotypes. On the final day of imaging, contralateral barrel cortex (where the imaging was performed) was marked with a toluidine blue solution and processed for electron microscopy. Synapses were quantified both in the ipsilateral (spared) as well as in the contralateral (deprived) barrel cortex. We characterized synapses to excitatory or inhibitory synapses based on the following criterion: (1) the morphology of synaptic vesicles on the presynaptic processes; and (2) the density and thickness of postsynaptic membrane (component). Excitatory synapses tend to have numerous spheroid vesicles, whereas the inhibitory synapses contain fewer ovoid (flat) synaptic vesicles in their presynaptic compartment (Gray, 1959a,b). Additionally, compared with inhibitory synapses, the postsynaptic membrane in excitatory synapses shows increased density and thickening along the length over which the presynaptic and postsynaptic membranes are opposed. Excitatory synapses are made mostly on dendritic spines and sometimes also on dendrites (axodendritic synapses). Although most of the spines that we analyzed by electron microscopy were spine synapses, in our analyses we also included axodendritic synapses if they displayed characteristics of an excitatory synapse. Differences in synaptic density were expressed as the percentage of change, which was presumed to be $100 \%$ for Thy1GFP (wild-type) mice. Quantitative EM analysis revealed that R6/2*Thy1-GFP mice, compared with Thy1-GFP mice, demonstrate significantly lower synaptic density both in spared as well as in deprived barrel cortex $\left(F_{(1,12)}=82.49 ; p<0.0001 ; N=4\right.$ mice/group; effect of genotype; two-way ANOVA; Fig. 3A-E). Moreover, in the Thyl-GFP mice, synaptic density was comparable between the spared and deprived barrel cortex (Fig. $3 A$ ). However, in the R6/2* Thyl-GFP mice, we observed an $\sim 58 \%$ reduction in synaptic density in the spared cortex and a further $\sim 15 \%$ reduction in synaptic density in the deprived cortex compared with the Thyl-GFP mice (synaptic density: Thyl-GFP mice spared, $39.88 \pm 0.33$; Thy1-GFP mice deprived, $39.34 \pm 3.7$; R6/2*Thy1-GFP mice spared, $23 \pm 1.4$; R6/2*Thyl-GFP mice deprived, $17.20 \pm 1.4$; Fig. $3 A$ ). Next, we performed immunoelectron microscopy using antibodies against presynaptic and postsynaptic markers (e.g., synaptophysin, VGLUT1, and PSD95) to determine whether there was any difference in the expression of these proteins in the excitatory synapses of Thyl-GFP and R6/2Thy1-GFP mice. By immuno-EM we found that most of the Thy1-GFP (wild-type) synapses retained PSD-95; however, most of the synapses in the R6/2^Thyl-GFP mice completely lacked PSD-95 (Fig. $3 F, G$ ). Only a very few synapses retained PSD-95 in the somatosensory cortical neurons of R6/2*Thy1GFP mice compared with the wild-type Thy1-GFP mice (Fig. $3 F, G)$. Additionally, we did not find any PSD-95-positive gold particles in our negative controls (BSA only, Thy1-GFP and R6/ $2^{\star}$ Thyl-GFP groups) where no primary antibody was used confirming the specificity of the PSD-95 antibody used in this study (Fig. $3 \mathrm{H}, I$ ). In addition, no significant difference in the expression of other synaptic markers such as synaptophysin and VGLUT1 was observed between the Thy1-GFP and R6/2Thy1GFP mice (data not shown). This suggests that the changes we observe in R6/2*Thyl-GFP mouse synapses are restricted to PSD-95 levels. In conclusion, our data suggest that synaptic deprivation exacerbates true loss of synapses and loss of postsynap- 
A

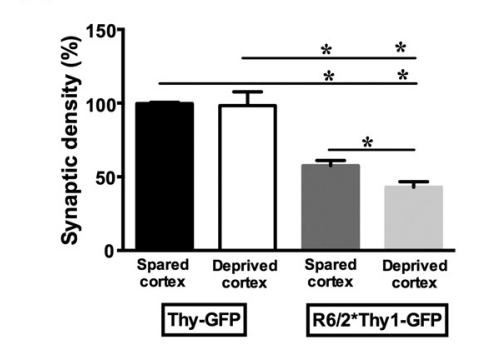

D my

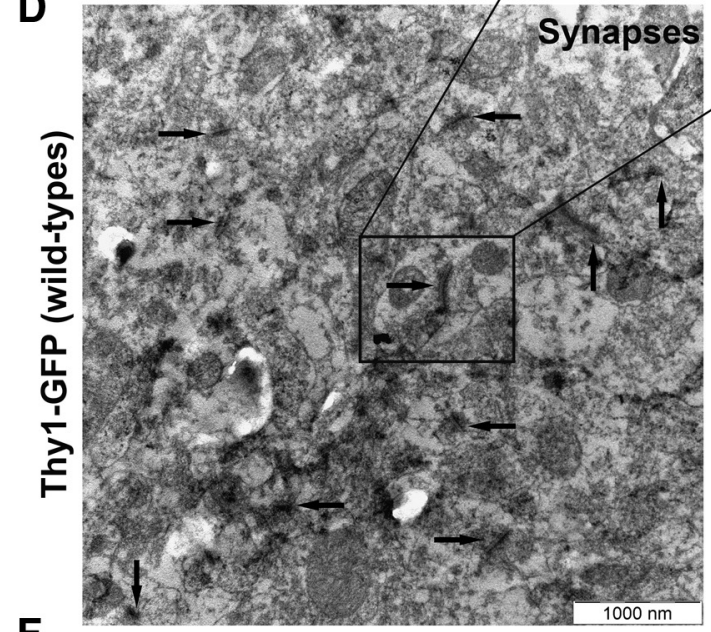

$\mathbf{F}$



H
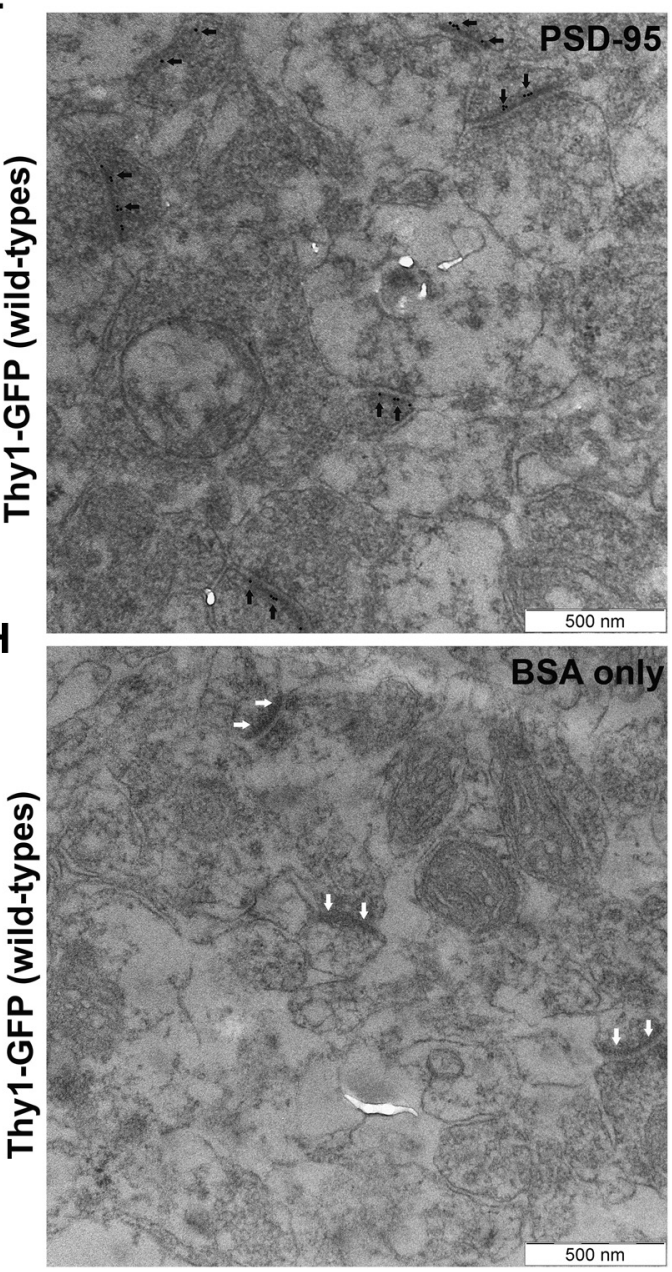

C
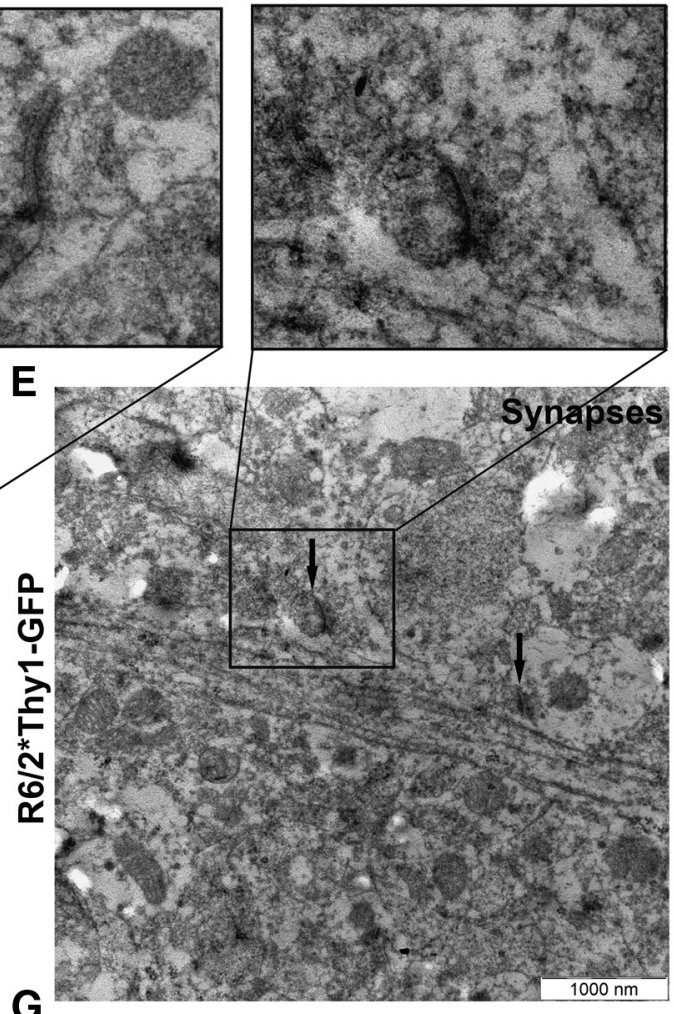

G
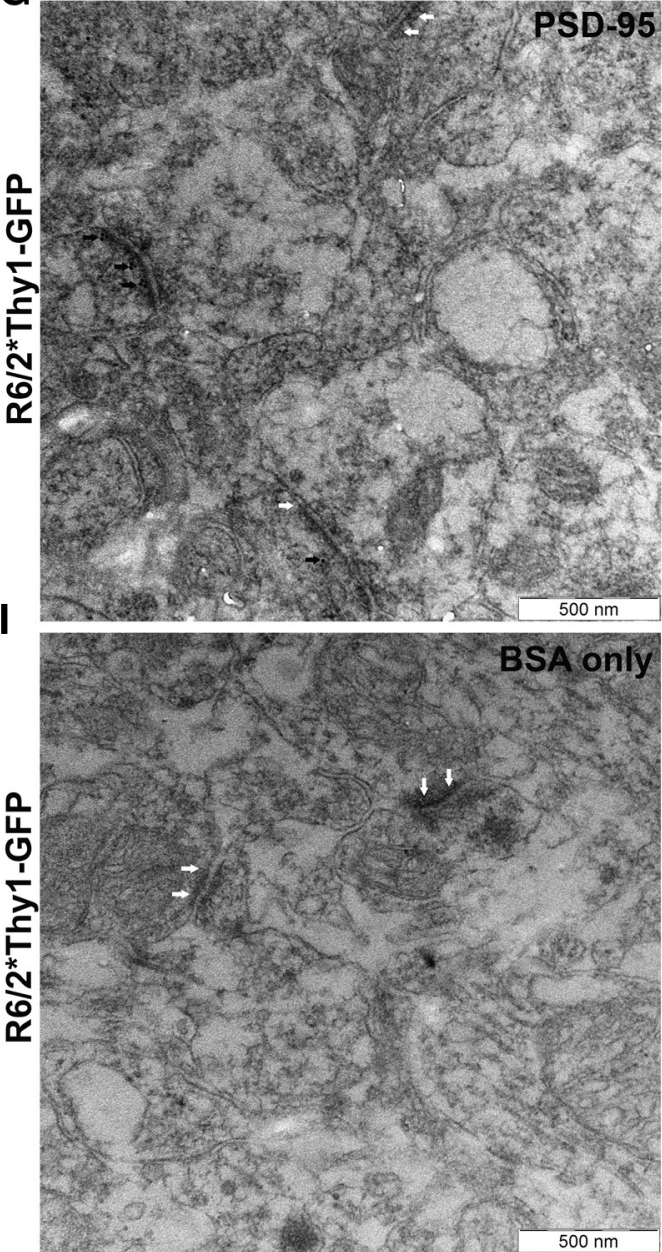
tic markers (mainly PSD-95) in the barrel cortical neurons of R6/2 mice.

\section{Significant reduction in PSD-95 (postsynaptic scaffolding protein) protein levels as the disease progressed in R6/2 mice compared with wild-type littermates}

Maintenance and stabilization of dendritic spines are regulated by synaptic activity as well as by the molecular complex at the postsynaptic density of spines (Yoshihara et al., 2009). The postsynaptic density protein PSD-95 is highly enriched in dendritic spines and has been associated with spine stability (Ehrlich et al., 2007). Interestingly, significant reductions in PSD-95 mRNA and protein level have been reported in several brain areas of HD patients and HD transgenic mice (Cha et al., 1998; Sun et al., 2001; Luthi-Carter et al., 2003). Additionally, $\beta$-actin, which is an essential component of cytoskeleton-forming dendritic spines, is altered in Huntington's disease (Lynch et al., 2007). The motility of dendritic spines is highly dependent on actin dynamics, and impaired actin dynamics have been reported in Huntington's disease models (Matus, 2000; Lynch et al., 2007; Sekino et al., 2007). To evaluate the mechanisms underlying the loss of persistent spines and impaired transformation of newly generated spines into persistent spines (after sensory deprivation in $\mathrm{R} 6 / 2$ mice), we performed Western blotting at three different ages $(6$, 8 , and 12 weeks) to compare PSD-95 and $\beta$-actin levels (relative to $\alpha$-tubulin levels) between wild-type littermates and R6/2 mice as the disease progressed. In both genotypes, we first analyzed PSD-95, $\beta$-actin, and $\alpha$-tubulin levels in the deprived cortex (contralateral, right hemisphere) as well as in the spared cortex (ipsilateral, left hemisphere) separately at 6, 8, and 12 weeks. Since we did not observe any significant difference in PSD-95, $\beta$-actin, and $\alpha$-tubulin levels between spared and deprived cortices in both genotypes, we pooled the data from both hemispheres

\footnotetext{
Figure 3. Sensory deprivation exacerbates the loss of synapses on barrel cortical neurons of R6/2 mice. A, Synaptic density expressed as a percentage of change, which is presumed to be $100 \%$ for wild-type (Thy1-GFP) mice. In R6/2*Thy1-GFP mice, synaptic density is significantly lower compared with Thy1-GFP mice. Further, in the Thy1-GFP mice, synaptic density is comparable between the two hemispheres (spared and deprived cortex); whereas, in the R6/ $2 *$ Thy1-GFP mice, synaptic density is $\sim 15 \%$ lower in the deprived cortex compared with the spared cortex. $\boldsymbol{B}, \boldsymbol{C}$, Higher-magnification $(43,000 \times)$ EM micrographs taken from the deprived cortex of a Thy1-GFP mouse $(\boldsymbol{B})$ and from the deprived cortex of an R6/2*Thy1-GFP mouse ( $\boldsymbol{C}$. Insets are highlighted to show the detailed morphology of the synapse. $D$, Low-magnification $(21,500 \times)$ EM micrograph from a Thy1-GFP mouse, showing numerous asymmetric synapses (marked by black arrows) in the deprived cortex. E, Low-magnification (21,500 X) EM micrograph from an R6/2*Thy1-GFP mouse, showing fewer asymmetric synapses (marked by black arrows) in the deprived cortex. Note the presence of 10 asymmetric synapses with thick postsynaptic densities in the Thy1-GFP mouse ( $\boldsymbol{D}$, left) compared with two asymmetric synapses in the R6/2*Thy1-GFP mouse ( $\boldsymbol{E}$, right). $\boldsymbol{F}$, Immunoelectron micrographs (taken at $43,000 \times$ ) demonstrating numerous PSD-95 (postsynaptic marker)-positive gold particles in the postsynaptic density of neurons localized in the deprived barrel cortex of Thy1-GFP mouse. Most synapses (or postsynaptic densities) in the Thy1-GFP mouse contain PSD-95-positive gold particles. G, Immunoreactivity of PSD-95 in the R6/2*Thy1-GFP mouse showing fewer PSD-95-positive gold particles in the postsynaptic density of their deprived barrel cortical neurons. Note that in the Thy1-GFP mouse all the synapses (six synapses in the representative image, $\boldsymbol{F}$ ) contain PSD-95 in their postsynaptic density (marked by black arrows). On the contrary, in R6/2 mice (as shown in the representative image, $\mathbf{G}$ ), only one synapse in three retains PSD-95-positive gold particles in the postsynaptic density (marked by black arrows); whereas, two other synapses show reductions in PSD-95 levels in their postsynaptic density (white arrows indicate the absence of PSD-95 in the postsynaptic density). $\boldsymbol{H}, \boldsymbol{I}$, Immunoelectron micrographs showing the complete absence of PSD-95-positive gold particles in the negative control groups, Thy1-GFP $(\boldsymbol{H})$ and R6/2*Thy1-GFP $(\boldsymbol{I})$ mice where only BSA and no primary antibody was used. Notice the total lack of PSD-95-positive dots in synapses indicated by white arrows. Data are presented as the mean \pm SEM. $N=4$ mice $/$ group.
}

for statistical analyses. Two-way ANOVAs revealed significant effects of genotype and age on the expression of PSD-95 protein levels, relative to $\beta$-actin $\left(F_{(1,20)}=38.4 ; p=0.001\right.$ for effect of genotype; $F_{(2,20)}=9.27 ; p=0.0011$ for effect of age; $N=3$ mice/group and relative to $\alpha$-tubulin; $F_{(1,10)}=166,7 ; p<0.0001$ for effect of genotype; and $F_{(2,20)}=13,62 ; p=0.0002$ for effect of age; $N=3$ mice/group). Quantification of normalized PSD-95 showed that, relative to $\beta$-actin and $\alpha$-tubulin at all ages analyzed (weeks 6, 8 and 12), R6/2 mice had significantly lower PSD-95 levels compared with the wild types (Fig. $4 A, B, D$ ). Already at week 6, PSD-95 protein levels were significantly lower in the R6/2 mice compared with wild-type littermates (Fig. $4 A, B$ ). As the disease progressed, we found time-dependent worsening (reduction) of PSD-95 levels in the R6/2 mice compared with wild-type littermates (Fig. $4 A, B ; p<0.05 ; N=3$ mice/group). Interestingly, quantification of normalized $\beta$-actin showed that at all ages analyzed the expression of $\beta$-actin (relative to $\alpha$-tubulin) did not significantly differ in the brain samples of R6/2 mice compared with their wild-type littermates (Fig. $4 C, D$ ). These data suggest that in our HD model R6/2 there is a significant reduction particularly in PSD-95 protein levels that is evident at a very early phase and that continues to be reduced as the disease progressed. PSD-95 reductions in the R6/2 mice could represent mechanisms underlying the dendritic spine pathology observed in this study.

\section{Significant reduction in PSD-95 and $\beta$-actin protein levels in the synapses of R6/2 mice compared with wild-type littermates}

To further investigate whether the PSD-95 reductions that we observed in our R6/2 mouse brain (by Western blot using total cell lysate) reflects true loss of PSD-95 from the synapses, we performed subcellular fractionation on cortical samples of both genotypes. By subcellular fractionation, we analyzed PSD-95 and $\beta$-actin protein levels (using $\alpha$-tubulin as a reference protein) in the synaptosome of both genotypes (R6/2 and wild-type mice) in their deprived cortex as well as in their spared cortex. Since, no significant differences in PSD-95 and $\beta$-actin protein levels were observed between the deprived and spared cortices in both genotypes, the data from both hemispheres were pooled for statistical analysis. Two-way ANOVAs revealed a significant effect of genotype on the expression level of PSD-95 $\left(F_{(1,20)}=337 ; P=<\right.$ $0.0001 ; N=3$ mice/group $)$ as well as $\beta$-actin $\left(F_{(1,20)}=36.82 ; p=\right.$ $0.0001 ; N=3$ mice/group) in the synaptosomes. Quantification of normalized PSD-95 showed that in the synaptosomes of R6/2 mice, the level of PSD-95 is significantly reduced at all ages (weeks 6,8 , and 12) compared with wild-type littermates (Fig. 4E, G-I; $p<0.001 ; N=3$ mice/group). Although there were no significant reductions in the overall $\beta$-actin levels in the R6/2 mouse brain (as indicated by Western blot on total cell lysate), $\beta$-actin levels were dramatically reduced in the synaptosomes of R6/2 mice compared with wild-type littermates (Fig. 4F-I). Further, proteins levels of both PSD-95 and $\beta$-actin were maintained at lower levels as the disease progressed in the R6/2 mice (Fig. 4E-I). These data confirm our EM findings, suggesting that in the cortical synapses of R6/2 mice there is a significant reduction in PSD-95 levels (in addition to the reduction of $\beta$-actin levels in the synapse), which could be the plausible mechanisms underlying dendritic spine pathology observed in our study.

\section{Discussion}

Synaptic activation regulates highly localized effects on synapses including local translation of synaptic proteins, recruitment, and targeted degradation, which are essential for the long-term plas- 
A

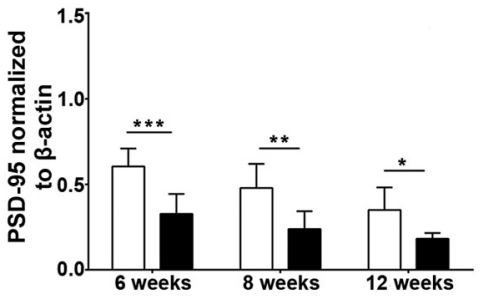

D
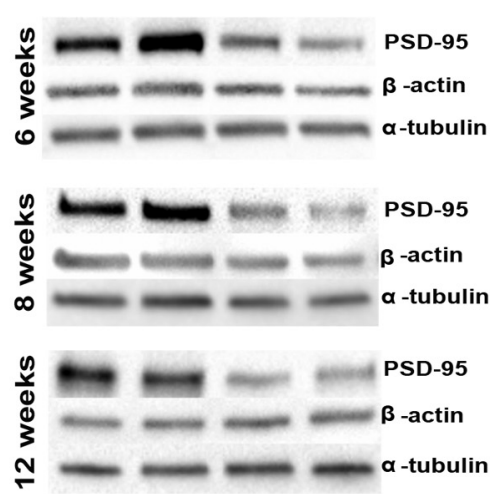

Wild-type Wild-type R6/2 R6/2

$\begin{array}{llll}\text { (Dpr) (Spr) (Dpr) (Spr) } & \end{array}$

G

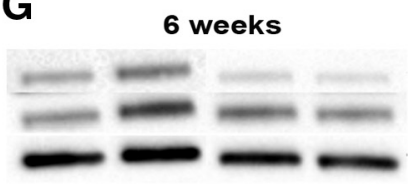

Wild-type Wild-type $R 6 / 2 \quad R 6 / 2$

$\begin{array}{llll}\text { (Dpr) (Spr) (Dpr) (Spr) } & \end{array}$
B

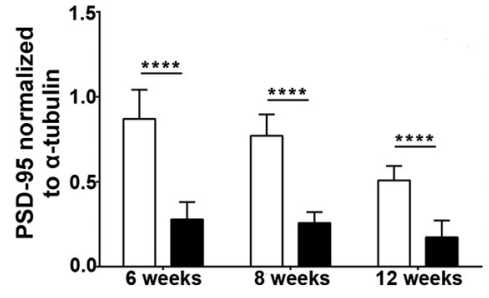

E
C
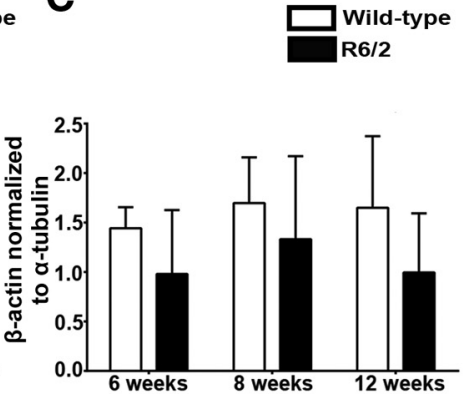

F

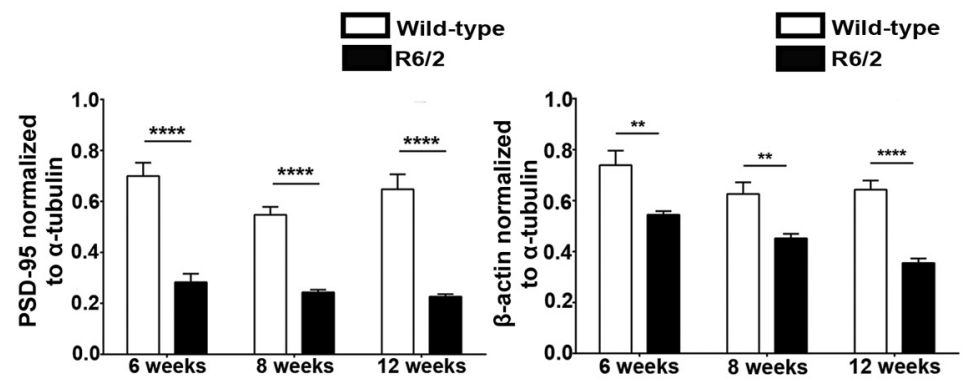

H

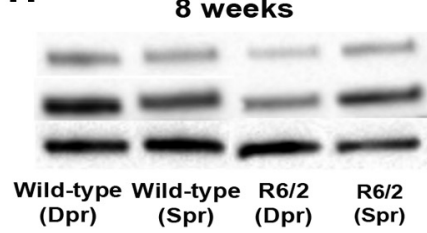

I

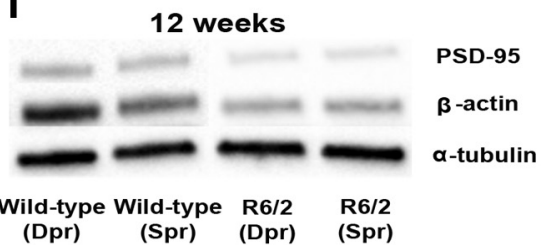

Figure 4. Reduced level of postsynaptic scaffolding protein PSD-95 in the R6/2 mice compared with the wild-type littermates. $A, B$, Quantification of normalized total PSD-95 protein: normalized to $\beta$-actin $(\boldsymbol{A})$ and to $\alpha$-tubulin (B) in the barrel cortex of R6/2 and wild-type mice at 6, 8, and 12 weeks. Data from deprived (contralateral hemisphere) and spared (ipsilateral hemisphere) cortices are pooled, since no significant differences were observed between the hemispheres. At all ages analyzed, R6/2 mice display significant reduction in PSD-95 protein levels compared with the wild-type littermates. Notice that already at week 6 (presymptomatic phase), R6/2 mice display significant reductions in PSD-95 levels compared with the wild-types littermates. C, Quantification of normalized total $\beta$-actin levels in the barrel cortex of R6/2 and wild-type mice at 6, 8, and 12 weeks. Data from deprived (contralateral hemisphere) and spared (ipsilateral hemisphere) cortices are pooled, since no significant differences were observed between the hemispheres. Note that at all ages analyzed, there is no significant difference in the expression of $\beta$-actin protein (relative to $\alpha$-tubulin) in the brain samples of R6/2 mice compared with wild-type littermates. $D$, Western blot image comparing PSD-95 and $\beta$-actin protein levels (relative to $\alpha$-tubulin levels) independently at different ages, as follows: 6, 8, and 12 weeks in the deprived and spared cortices of wild-type and R6/2 mice. A reduced level of PSD-95 is evident at weeks 6,8 , and 12 in both the deprived barrel cortex as well as the spared barrel cortex of R6/2 mice (no difference between hemispheres) compared with wild-type mice. Dpr, Deprived cortex; Spr, spared cortex. E, F, Quantification of normalized PSD-95 $(\boldsymbol{E})$ and $\beta$-actin $(\boldsymbol{F})$ levels in the synaptosomal fraction of R6/2 mice compared with wild-type littermates at weeks 6, 8, and 12. PSD-95 and $\beta$-actin levels are normalized to $\alpha$-tubulin. Significant reductions in PSD-95 and $\beta$-actin protein levels are evident in the synaptosome of R6/2 mice compared with wild-type littermates at all ages. G-I, Western blot image representing the expression level of PSD-95 and $\beta$-actin (relative to $\alpha$-tubulin) in the synaptosomal fraction of R6/2 mice compared with wild-type littermates at weeks 6 (G), $8(\boldsymbol{H})$, and 12 (I). At all ages, significantly lower levels of PSD-95 and $\beta$-actin are observed in the synaptosome of R6/2 mice compared with the wild-type littermates. $N=3$ mice/group. Data are presented as the mean \pm SEM. Means were considered to be statistically significant at $p<0.05$. Asterisks indicate significant differences between groups.

ticity and synaptic maturation that forms the basis of memory formation and storage in the brain (Bramham, 2008). Blocking synaptic input (by whisker trimming) causes experiencedependent reorganization of neuronal circuitry whereby "old connections," represented by previously existing persistent spines, are destabilized and "new connections," represented by new persistent spines, are favored (Fox and Wong, 2005; Holtmaat et al., 2006). Previously, we have shown that in the absence of any sensory manipulation (i.e., baseline neuronal activity), a progressive loss, particularly of persistent spines, occurs in the neocortex of R6/2 mice throughout the disease (Murmu et al., 2013). Here, we used a sensory deprivation paradigm (for the inhibition of synaptic input) together with in vivo two-photon imaging to explore the relationship between structural spine plasticity and experience-dependent plasticity as the disease progressed in an HD mouse model (R6/2), which had been crossed with a reporter mice (Thy1-GFPM) for visualization and imaging of cortical neurons.

There are three main findings of this study. First, blocking synaptic input by whisker trimming exacerbated the loss of persistent-type, stable spines only in HD mice (R6/2*Thy1-GFP mice), but not in Thyl-GFP (wild-type) mice. Persistent spine loss in R6/2*Thy1-GFP mice after whisker trimming was $\sim 37 \%$ greater compared with Thy1-GFP mice. Second, while the gener- 
ation of new spines was not impaired, the transformation of newly formed spines into persistent spines was severely impaired in R6/2*Thy1-GFP mice. In contrast to wild-type Thy1-GFP mice, R6/2*Thy1-GFP mice (both trimmed and untrimmed) continued to gain new spines. However, the probability of new spines becoming persistent was significantly reduced in R6/2 mice. As a consequence, very few of those newly formed spines transformed into persistent spines in these mice, suggesting that inhibition of synaptic input induces improper tuning of synaptic circuitry in R6/2 mice, whereby the mechanism underlying the generation of new spines is unaffected, but the mechanism underlying dendritic spine stabilization is impaired. Additionally, we observed significant reductions in PSD-95 levels in R6/2 mouse brains (both spared and deprived cortex), which was evident very early in the disease phase and became worse as the disease progressed. Reductions in PSD-95 levels were observed, particularly in the cortical synapses of R6/2 mice compared with wild-type littermates. In addition, a significant reduction in $\beta$-actin was also observed, although only in the cortical synapse of R6/2 mice. Interestingly, reductions in PSD-95 and spine pathology seem to occur around the same time (6 weeks) in our R6/2 mice, indicating that the loss of PSD-95 could underlie the spine pathology observed in our study. Finally, our results suggest that synaptic inhibition exacerbates the loss of excitatory synapses in R6/2 mice. These mice display $\sim 15 \%$ fewer synapses in their deprived barrel cortex compared with their spared barrel cortex, which also shows reduced synaptic density ( $~ 58 \%)$ compared with wild types.

It is unclear why inhibiting synaptic input in HD would interfere with the normal plasticity of dendritic spines. Further investigations are needed to address why deprivation of synaptic input in HD would exacerbate the loss of persistent spines or synapses and impair the transformation of newly generated spines into persistent spines. However, several mechanisms could be implicated. Although HD is an autosomal-dominant genetic disease, it is affected by environmental factors. Monozygotic twins with HD and identical CAG-repeat lengths can display distinctly different clinical symptoms and behavioral abilities (Georgiou et al., 1999). Further, remotivation therapy, which mentally stimulates patients, benefits HD sufferers and environmental enrichment via sensory, motor and cognitive stimulations is known to delay disease onset and slow progression in HD transgenic mice (van Dellen et al., 2000; Sullivan et al., 2001; Hockly et al., 2002; Spires et al., 2004a). Environmental enrichment also increases cortical volume and induces the expression of genes involved in synaptic function and cellular plasticity in HD transgenic mice (Spires et al., 2004a). In contrast, very little is known about the effect of environmental deprivation in HD. It is likely that environmental deprivation or deprivation of sensory input would exert an opposing effect on motor and cognitive as well as on the molecular and morphological aspects in HD. Studies show that in neurodegenerative disorders, like Alzheimer's disease, synaptic inhibition increases secretion of the pathological form of $\mathrm{A} \beta$ (mutant protein) and exacerbates the loss of synaptic proteins such as synaptophysin, causing synaptic dysfunction and memory impairment (Tampellini et al., 2010). It is likely that inhibiting synaptic activity by blocking sensory input would change the synaptic load of mutant huntingtin, which in turn might exacerbate the loss of proteins that maintains and supports persistent spines. Maintenance and stabilization of dendritic spines are regulated by synaptic activity, as well as by the molecular complex at the PSD of spines, consisting of neurotransmitter receptors, scaffolding proteins (PSD-95), enzymes, and cytoskeletal proteins (Yoshihara et al., 2009). Close correlation exists among spine head size, PSD size, AMPA receptor number, and spine stability; a phenomenon that possibly shows similarities to LTP (Yoshihara et al., 2009). Interestingly, we observed a significant reduction in the level of the postsynaptic scaffolding protein PSD-95 and also actin in the brain (particularly, in the synapse) of $\mathrm{R} 6 / 2$ mice, as previously reported in HD patients and in HD transgenic mice (Cha et al., 1998; Sun et al., 2001; Luthi-Carter et al., 2003). Reductions in PSD-95 in our HD model occurred in the presymptomatic phase during which spine pathology also becomes evident. PSD-95 is highly enriched in dendritic spines and has been associated with spine stability (Prange and Murphy, 2001; Ehrlich et al., 2007). Studies show that spines with low levels of PSD-95 are more dynamic, and the recruitment of PSD-95 to nascent spines has been associated with spine stabilization (Ehrlich et al., 2007). Based on these findings, we speculate that the reduced PSD-95 and actin levels in the barrel cortex of R6/2 mice could underlie persistent spine loss and failure in the stabilization of new spines into persistent spines in these mice. Studies show that synaptic inhibition in a normal mouse does not affect the level of PSD-95 protein in the brain (Butko et al., 2013).

Mutant huntingtin has the propensity to aggregate and sequester proteins regulating synaptic transmission such as PSD-95 and AMPA. We have previously shown that mutant huntingtin is directly involved in the loss of mature-type, stable spines in cortical-hippocampal cultures in vitro (Murmu et al., 2013). By sequestering key proteins, mutant huntingtin could deplete these proteins at their site of action, thereby causing the spine pathology or persistent spine loss observed in our study. Further, mutant huntingtin inclusions in the nucleus could influence the transcription of genes involved in the maintenance and regulation of mature-type, persistent spines. By reducing key synaptic proteins, mutant huntingtin might induce maladaptive experiencedependent reorganization of synaptic circuitries. Interestingly, abnormal synaptic plasticity during the early presymptomatic phase has been reported in several animal models of HD (Murphy et al., 2000; Spires et al., 2004b; Milnerwood and Raymond, 2007). Further, deficit in a learning task, which requires intact barrel cortex, has also been reported in an HD animal model (Mazarakis et al., 2005). Another mechanism, by which the loss of mature spines in cultured neurons is reported to occur, is via defective endosomal trafficking. Richards et al., 2011 have demonstrated that mutant huntingtin aggregates associate with mature spines, leading to their loss. Hence, it is likely that defective endosomal trafficking could underlie observed spine pathology. Additionally, various other proteins regulating synaptic transmission, which are also dysregulated in HD patients and HD transgenic mice, could be involved in the observed spine pathology (Nithianantharajah et al., 2009; Nithianantharajah and Hannan, 2013). Last, in this study we could show that persistent spine loss induced by whisker trimming in R6/2*Thy1-GFP mice was not related to the disease state, but rather to the deprivation of sensory inputs (whisker-barrel). Age-matched untrimmed R6/ $2^{\star}$ Thy1-GFP mice lose $\sim 21 \%$ less persistent spines compared with the trimmed R6/2*Thy1-GFP mice. This indicates the driving force of sensory-dependent mechanism over development of disease phenotypes (as shown previously for environmental enrichment), implying that the manipulation of sensory inputs or activity strength may be used as a therapeutic intervention in HD.

In conclusion, we report that the pathological processes of HD interfere with the normal plasticity and fine tuning of dendritic spines in response to sensory deprivation. Our results suggest 
experience-dependent improper tuning of neuronal circuitry in HD. Further, our results provide a plausible mechanism of spine loss in the HD model. It is possible that the observed changes in synapses corresponds to a much larger fractional change in the connectivity in HD that could lead to functional changes in cortical neurons and change their output characteristics. It is likely that experience-dependent alterations in structural and mechanistic levels that we report in our HD model R6/2 might represent the neural mechanism underlying the cognitive deficit observed in HD. Therapies that stabilize dendritic spines or promote spine maturation, together with manipulations that involve the regulation of synaptic inputs or activity, may be beneficial for the treatment of early symptoms, such as cognitive deficits, in HD.

\section{References}

Bramham CR (2008) Local protein synthesis, actin dynamics, and LTP consolidation. Curr Opin Neurobiol 18:524-531. CrossRef Medline

Butko MT, Savas JN, Friedman B, Delahunty C, Ebner F, Yates JR $3^{\text {rd }}$, Tsien RY (2013) In vivo quantitative proteomics of somatosensory cortical synapses shows which protein levels are modulated by sensory deprivation. Proc Natl Acad Sci U S A 110:E726-E735. CrossRef Medline

Cha JH, Kosinski CM, Kerner JA, Alsdorf SA, Mangiarini L, Davies SW, Penney JB, Bates GP, Young AB (1998) Altered brain neurotransmitter receptors in transgenic mice expressing a portion of an abnormal human Huntington disease gene. Proc Natl Acad Sci U S A 95:6480-6485. CrossRef Medline

De Paola V, Holtmaat A, Knott G, Song S, Wilbrecht L, Caroni P, Svoboda K (2006) Cell type-specific structural plasticity of axonal branche and boutons in the adult neocortex. Neuron 49:861-875. CrossRef Medline

Ehrlich I, Klein M, Rumpel S, Malinow R (2007) PSD-95 is required for activity-driven synapse stabilization. Proc Natl Acad Sci U S A 104:41764181. CrossRef Medline

Feng G, Mellor RH, Bernstein M, Keller-Peck C, Nguyen QT, Wallace M, Nerbonne JM, Lichtman JW, Sanes JR (2000) Imaging neuronal subsets in transgenic mice expressing multiple spectral variants of GFP. Neuron 28:41-51. CrossRef Medline

Ferrante RJ, Kowall NW, Richardson EP Jr (1991) Proliferative and degenerative changes in striatal spiny neurons in Huntington's disease: a combined study using the section-Golgi method and calbindin D28k immunocytochemistry. J Neurosci 11:3877-3887. Medline

Fox K, Wong RO (2005) A comparison of experience-dependent plasticity in the visual and somatosensory systems. Neuron 48:465-477. CrossRef Medline

Georgiou N, Bradshaw JL, Chiu E, Tudor A, O'Gorman L, Phillips JG (1999) Differential clinical and motor control function in a pair of monozygotic twins with Huntington's disease. Mov Disord 14:320-325. CrossRef Medline

Glazewski S, Fox K (1996) Time course of experience-dependent synaptic potentiation and depression in barrel cortex of adolescent rats. J Neurophysiol 75:1714-1729. Medline

Graveland GA, Williams RS, DiFiglia M (1985) Evidence for degenerative and regenerative changes in neostriatal spiny neurons in Huntington's disease. Science 227:770-773. CrossRef Medline

Gray EG (1959a) Electron microscopy of synaptic contacts on dendrite spines of the cerebral cortex. Nature 183:1592-1593. CrossRef Medline

Gray EG (1959b) Axo-somatic and axo-dendritic synapses of the cerebral cortex: an electron microscope study. J Anat 93:420-433. Medline

Heck N, Betuing S, Vanhoutte P, Caboche J (2012) A deconvolution method to improve automated 3D-analysis of dendritic spines: application to a mouse model of Huntington's disease. Brain Struct Funct 217: 421-434. CrossRef Medline

Hockly E, Cordery PM, Woodman B, Mahal A, van Dellen A, Blakemore C, Lewis CM, Hannan AJ, Bates GP (2002) Environmental enrichment slows disease progression in R6/2 Huntington's disease mice. Ann Neurol 51:235-242. CrossRef Medline

Holtmaat AJ, Trachtenberg JT, Wilbrecht L, Shepherd GM, Zhang X, Knott GW, Svoboda K (2005) Transient and persistent dendritic spines in the neocortex in vivo. Neuron 45:279-291. CrossRef Medline

Holtmaat A, Wilbrecht L, Knott GW, Welker E, Svoboda K (2006)
Experience-dependent and cell-type-specific spine growth in the neocortex. Nature 441:979-983. CrossRef Medline

Knott GW, Holtmaat A, Wilbrecht L, Welker E, Svoboda K (2006) Spine growth precedes synapse formation in the adult neocortex in vivo. Nat Neurosci 9:1117-1124. CrossRef Medline

Luthi-Carter R, Apostol BL, Dunah AW, DeJohn MM, Farrell LA, Bates GP, Young AB, Standaert DG, Thompson LM, Cha JH (2003) Complex alteration of NMDA receptors in transgenic Huntington's disease mouse brain: analysis of mRNA and protein expression, plasma membrane association, interacting proteins, and phosphorylation. Neurobiol Dis 14: 624-636. CrossRef Medline

Lynch G, Kramar EA, Rex CS, Jia Y, Chappas D, Gall CM, Simmons DA (2007) Brain-derived neurotrophic factor restores synaptic plasticity in a knock-in mouse model of Huntington's disease. J Neurosci 27:44244434. CrossRef Medline

Mangiarini L, Sathasivam K, Seller M, Cozens B, Harper A, Hetherington C, Lawton M, Trottier Y, Lehrach H, Davies SW, Bates GP (1996) Exon 1 of the HD gene with an expanded CAG repeat is sufficient to cause a progressive neurological phenotype in transgenic mice. Cell 87:493-506. CrossRef Medline

Matus A (2000) Actin-based plasticity in dendritic spines. Science 290:754758. CrossRef Medline

Mazarakis NK, Cybulska-Klosowicz A, Grote H, Pang T, Van Dellen A, Kossut M, Blakemore C, Hannan AJ (2005) Deficits in experience-dependent cortical plasticity and sensory-discrimination learning in pre-symptomatic Huntington's disease mice. J Neurosci 25:3059-3066. CrossRef Medline

Milnerwood AJ, Raymond LA (2007) Corticostriatal synaptic function in mouse models of Huntington's disease: early effects of huntingtin repeat length and protein load. J Physiol 585:817-831. CrossRef Medline

Murmu RP, Li W, Holtmaat A, Li JY (2013) Dendritic spine instability leads to progressive neocortical spine loss in a model of Huntington's disease. J Neurosci 33:12997-13009. CrossRef Medline

Murphy KP, Carter RJ, Lione LA, Mangiarini L, Mahal A, Bates GP, Dunnett SB, Morton AJ (2000) Abnormal synaptic plasticity and impaired spatial cognition in mice transgenic for exon 1 of the human Huntington's disease mutation. J Neurosci 20:5115-5123. Medline

Nithianantharajah J, Hannan AJ (2013) Dysregulation of synaptic proteins, dendritic spine abnormalities and pathological plasticity of synapses as experience-dependent mediators of cognitive and psychiatric symptoms in Huntington's disease. Neuroscience 251:66-74. CrossRef Medline

Nithianantharajah J, Barkus C, Vijiaratnam N, Clement O, Hannan AJ (2009) Modeling brain reserve: experience-dependent neuronal plasticity in healthy and Huntington's disease transgenic mice. Am J Geriatr Psychiatry 17:196-209. CrossRef Medline

Orth M, Schippling S, Schneider SA, Bhatia KP, Talelli P, Tabrizi SJ, Rothwell JC (2010) Abnormal motor cortex plasticity in premanifest and very early manifest Huntington disease. J Neurol Neurosurg Psychiatry 81: 267-270. CrossRef Medline

Prange O, Murphy TH (2001) Modular transport of postsynaptic density-95 clusters and association with stable spine precursors during early development of cortical neurons. J Neurosci 21:9325-9333. Medline

Richards P, Didszun C, Campesan S, Simpson A, Horley B, Young KW, Glynn P, Cain K, Kyriacou CP, Giorgini F, Nicotera P (2011) Dendritic spine loss and neurodegeneration is rescued by Rab11 in models of Huntington's disease. Cell Death Differ 18:191-200. CrossRef Medline

Schippling S, Schneider SA, Bhatia KP, Münchau A, Rothwell JC, Tabrizi SJ, Orth M (2009) Abnormal motor cortex excitability in preclinical and very early Huntington's disease. Biol Psychiatry 65:959-965. CrossRef Medline

Sekino Y, Kojima N, Shirao T (2007) Role of actin cytoskeleton in dendritic spine morphogenesis. Neurochem Int 51:92-104. CrossRef Medline

Spires TL, Grote HE, Varshney NK, Cordery PM, van Dellen A, Blakemore C, Hannan AJ (2004a) Environmental enrichment rescues protein deficits in a mouse model of Huntington's disease, indicating a possible disease mechanism. J Neurosci 24:2270-2276. CrossRef Medline

Spires TL, Grote HE, Garry S, Cordery PM, Van Dellen A, Blakemore C, Hannan AJ (2004b) Dendritic spine pathology and deficits in experience-dependent plasticity in R6/1 Huntington's disease transgenic mice. Eur J Neurosci 19:2799-2807. CrossRef Medline

Sullivan FR, Bird ED, Alpay M, Cha JH (2001) Remotivation therapy and Huntington's disease. J Neurosci Nurs 33:136-142. CrossRef Medline

Sun Y, Savanenin A, Reddy PH, Liu YF (2001) Polyglutamine-expanded 
huntingtin promotes sensitization of $\mathrm{N}$-methyl-D-aspartate receptors via post-synaptic density 95. J Biol Chem 276:24713-24718. CrossRef Medline

Tampellini D, Capetillo-Zarate E, Dumont M, Huang Z, Yu F, Lin MT, Gouras GK (2010) Effects of synaptic modulation on $\beta$-amyloid, synaptophysin, and memory performance in Alzheimer's disease transgenic mice. J Neurosci 30:14299-14304. CrossRef Medline

The Huntington's Disease Collaborative Research Group (1993) A novel gene containing a trinucleotide repeat that is expanded and unstable on Huntington's disease chromosomes. Cell 72:971-983. CrossRef Medline van Dellen A, Blakemore C, Deacon R, York D, Hannan AJ (2000) Delaying the onset of Huntington's in mice. Nature 404:721-722. CrossRef Medline
Wallace H, Fox K (1999) The effect of vibrissa deprivation pattern on the form of plasticity induced in rat barrel cortex. Somatosens Mot Res 16: 122-138. CrossRef Medline

Wilbrecht L, Holtmaat A, Wright N, Fox K, Svoboda K (2010) Structural plasticity underlies experience-dependent functional plasticity of cortical circuits. J Neurosci 30:4927-4932. CrossRef Medline

Woolsey TA, Van der Loos H (1970) The structural organization of layer IV in the somatosensory region (SI) of mouse cerebral cortex. The description of a cortical field composed of discrete cytoarchitectonic units. Brain Res 17:205-242. CrossRef Medline

Yoshihara Y, De Roo M, Muller D (2009) Dendritic spine formation and stabilization. Curr Opin Neurobiol 19:146-153. CrossRef Medline 